\title{
A dual-inlet, single detector relaxed eddy accumulation system for long-term measurement of mercury flux
}

\section{S. Osterwalder et al.}

Correspondence to: S. Osterwalder (stefan.osterwalder@unibas.ch)

The copyright of individual parts of the supplement might differ from the CC-BY 3.0 licence. 
This supplement consists of a table and 8 figures which complement the main article giving supporting information regarding the following topics:

- Table S1: To enable reproducibility of the system, the main REA components and their quantity, their manufacturing company, the county of origin and model number is given. The capital letters in the Index column of the table point to the components in Fig. 1 in the main text.

- Figure. S1: The manual calibration of the $\mathrm{Hg}$ detector was done after each measurement campaign in the laboratory in Basel and in situ at Degerö. Repeated injections of a GEM concentration to both air streams, every $30 \mathrm{~min}$, resulted in 8 and 18 data points for each linear regression fit in Basel and Degerö, respectively.

- Figure S2: Limitations in turbulence mixing were defined applying a turbulence characteristic test (Eq. 8). 6\% of the data in Basel and 4\% at Degerö were rejected due to insufficient turbulence. The threshold (green dotted lines) is defined as a deviation of 2 from the model. Measurements beyond that point were rejected.

- Figure S3: The systematic bias in "same-air" measurements caused by the sampling line offset was corrected for in the $\mathrm{Hg}^{0}$ flux calculation. The strict rejection criteria allow a maximum standard deviation of the offset of 0.05 and a maximum difference in gold cartridge response of $10 \%$. At both sites gold cartridge-pair 1-3 failed the bias test. In Basel the standard deviation of the offset was too high (Fig S3a, blue line) and at Degerö the difference in the gold cartridge response between $\mathrm{C} 1$ and $\mathrm{C} 2$ was greater than the defined threshold (Fig S3a, blue line).

- Figure S4: The substandard performance of cartridge-pair 1-3 was confirmed by plotting the difference between the updraft and downdraft integrated air samples to the updraft air sample. The cartridge-pair 1-3 data (blue dots) scatter considerably more compared to cartridge-pair 2-4 (red dots) indicating a malfunction in a piece of equipment (Teflon Isolation Valves in energized status).

- Figure S5: The polar histograms show how the $30 \mathrm{~min}$ averages of wind speed, GEM concentration and wind direction are distributed at both sites during the campaigns. The polar histograms a) and b) describe the situation in Basel and c) and d) at Degerö.

- Figure S6: The fast-response valve switching frequency (30 min average) was considerably higher at Degerö (red) compared to Basel (black) indicating the presence of smaller eddies. The switching interval tended to increase with increasing friction velocity.

- Figure S7: Turbulence regimes have been investigated at both sides. Integral REA flux damping factors dependent on wind speed and stability conditions were derived. The simulation indicates that considerable flux damping in Basel occurs just during unstable conditions and low wind velocities (a). At Degerö, the integral damping factor is considerable during stable conditions and high wind velocities (b).

- Figure S8: The total REA flux damping factor at average wind speeds at both sites increased with increasing wind speed during stable conditions. In Basel REA flux damping just occurred at very low frequency ranges. 
Table S1. Most important REA components. They are indexed in the text and in the schematic of the REA system hardware (Fig. 1) with capital letters.

\begin{tabular}{|c|c|c|c|c|c|}
\hline Index & Quantity & Components & Manufacturer & Country & Model number \\
\hline A1 & 1 & Sonic anemometer & Metek & GER & USA-1 \\
\hline A2 & 1 & Sonic anemometer & Gill Instruments & UK & Solent1012R2 \\
\hline B & 3 & Rocker Solenoid Valves (fast-response) & Bürkert Fluid Control Systems & GER & $6128+2507$ \\
\hline C & 1 & LabVIEW 2011 & National Instruments & USA & 22.6 .2011 \\
\hline D & $100 \mathrm{~m}$ & PTFE tubing $1 / 4^{\prime \prime}$ & VICI AG International & SUI & JR-T-6810 \\
\hline $\mathrm{E}$ & 3 & $0.2 \mu \mathrm{m}$ PTFE filters & Merck Millipore & GER & SLFG65010 \\
\hline $\mathrm{F}$ & 6 & $0.2 \mu \mathrm{m}$ PTFE filters & Pall Corporation & USA & Acro 50, 4400 \\
\hline G & 10 & Teflon Isolation Valves & N Research & USA & SH360T041 \\
\hline $\mathrm{H}$ & 1 & Pressure transmitter & WIKA & GER & $\mathrm{A}-10$ \\
\hline 1 & 3 & Red-y smart controller GSC & Vögtlin Instruments & SUI & 3214101 \\
\hline J & 1 & Rotary vane pump & Gardner Denver Gmbh & GER & G 08 \\
\hline K & 3 & Uniplast boxes & Swibox & SUI & UCP $540 / 750$ \\
\hline L & 1 & Dynacalibrator & VICI AG International & SUI & 150 \\
\hline M & 1 & CVAFS Hg Detector & TEKRAN Inc. & CAN & 2500 \\
\hline $\mathrm{N}$ & 1 & Swing piston vacuum pump & KNF Neuberger & GER & NPK 09 DC \\
\hline 0 & 1 & Pressure gauge with water trap & Servatechnik & SUI & - \\
\hline$P$ & 1 & $1 / 4 "$ Hydrocarbon trap & Chromatography R.S, Inc. & USA & 300 \\
\hline$Q$ & 201 & Argon gas (purity $>99.9997 \%$ ) & Air Liquide S.A. & FRA & N57 \\
\hline $\mathrm{R}$ & 1 & Hg Vapor Calibration Unit & TEKRAN Inc. & CAN & 2505 \\
\hline S & 1 & Digital gas-tight syringe & Hamilton & USA & 1700 \\
\hline $\mathrm{T}$ & 1 & Hg Zero-Air Generator & TEKRAN Inc. & CAN & 1100 \\
\hline
\end{tabular}





b

Figure S1. Linear relationship between detected GEM reference gas concentration on each of the four gold cartridges (Area, 1-4) and manually injected GEM [pg] for Basel (a) and Degerö (b). 

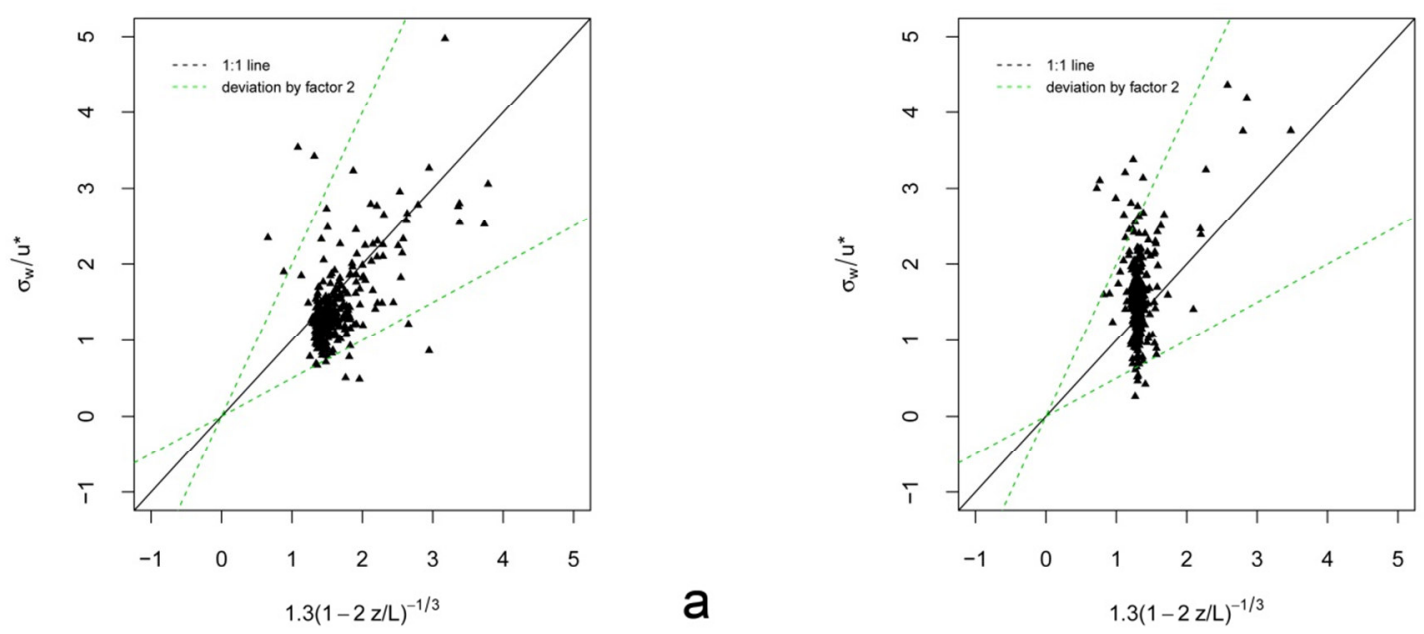

b

Figure S2. A deviation by more than a factor of 2 from the model (green dotted line) was used as the threshold to reject data measured in Basel (a) and Degerö (b) during periods of insufficient and larger than expected turbulence. 

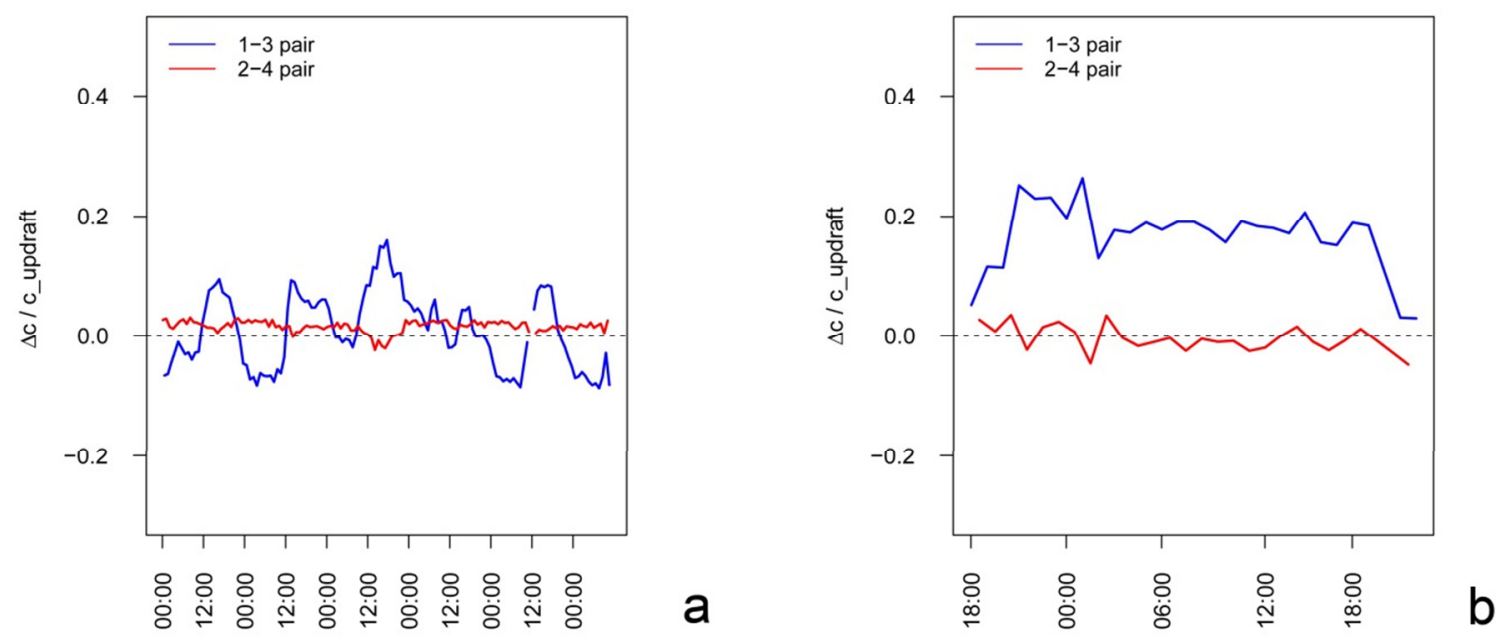

Figure S3. Precision in concentration difference measurements of the same GEM concentration between cartridge-pair 1-3 (blue) and 2-4 (red) in Basel (a) and at Degerö (b). 

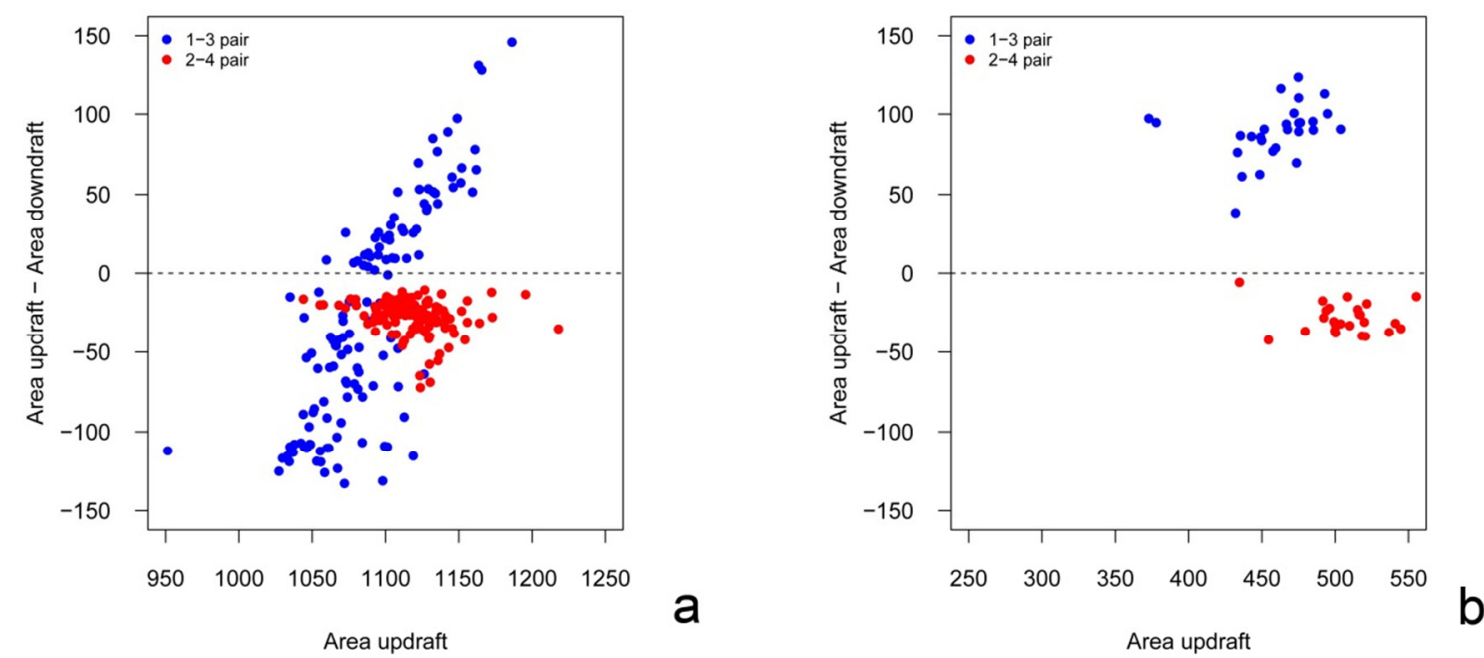

Figure S4. Ratio of the difference between the updraft and downdraft integrated air sampling to the updraft signal for both cartridge-pairs during the bias test in Basel (a) and Degerö (b). 


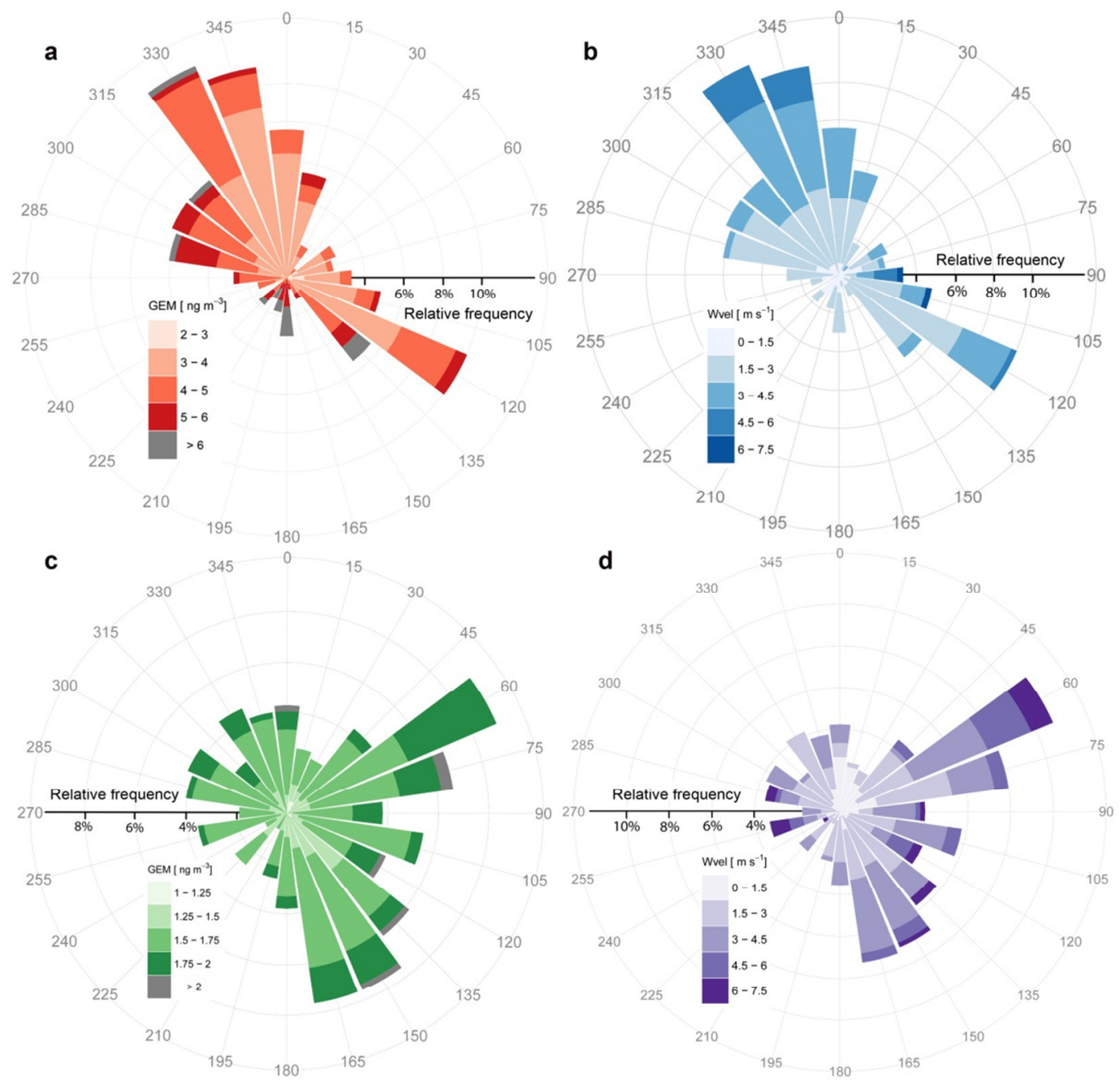

Figure S5. GEM concentration (A) and wind rose (B) during the Basel campaign and GEM concentration (C) and wind rose (D) during the Degerö campaign. Polar histograms show 30 min averaged GEM concentrations $\left(\mathrm{ng} \mathrm{m}^{-3}\right)$ and wind speed $\left(\mathrm{m} \mathrm{s}^{-1}\right)$. 


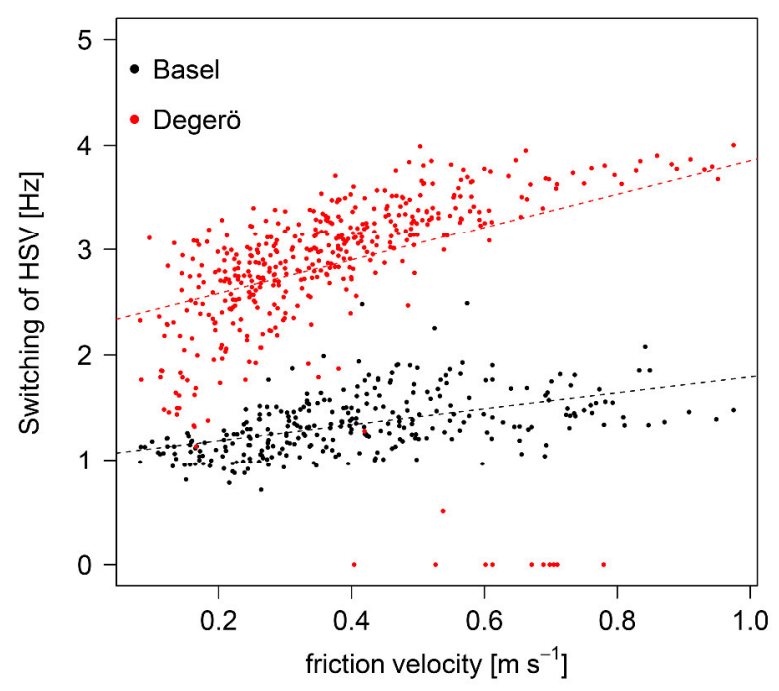

Figure S6. 30-min averaged switching frequency of fast-response valves (HSV) at Basel (black) and Degerö (red) in relation to friction velocity. 

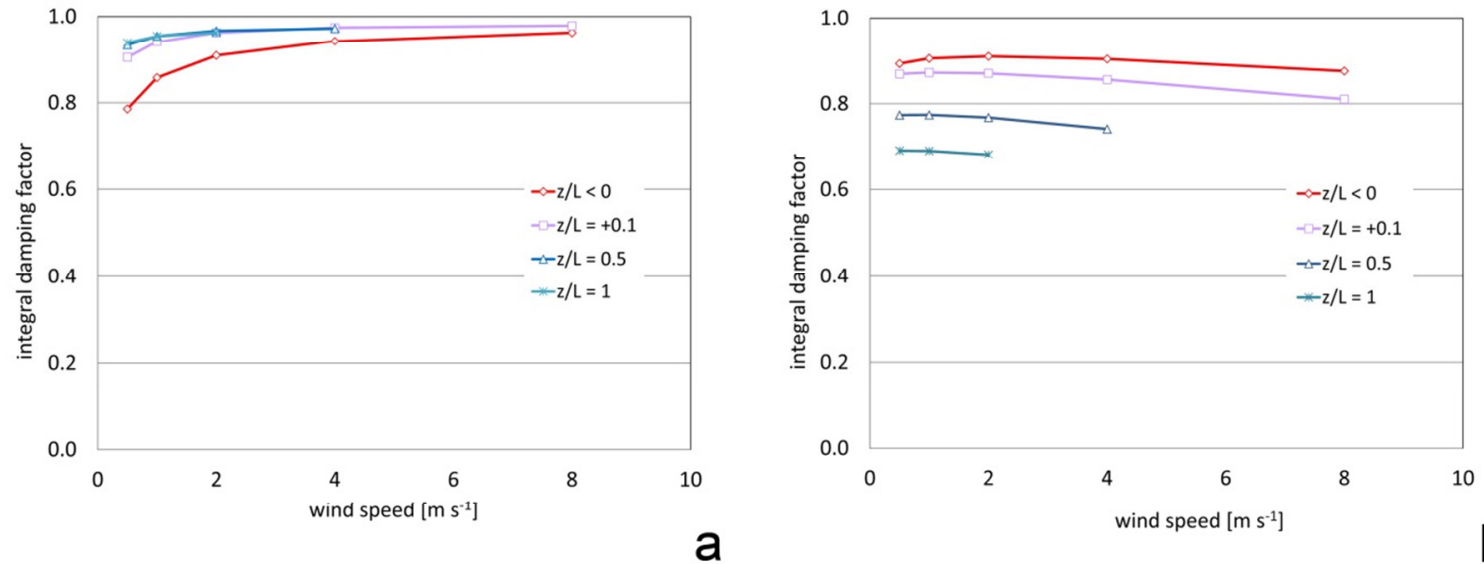

a

b

Figure S7. Simulated integral damping factors for REA fluxes in Basel (a) and Degerö (b) dependent on wind speed $\left(0-10 \mathrm{~m} \mathrm{~s}^{-1}\right)$ and stability conditions: Unstable $(\mathrm{z} / \mathrm{L}<0)$; stable $(\mathrm{z} / \mathrm{L}$ $=0.1, \mathrm{z} / \mathrm{L}=0.5, \mathrm{z} / \mathrm{L}=1)$. 

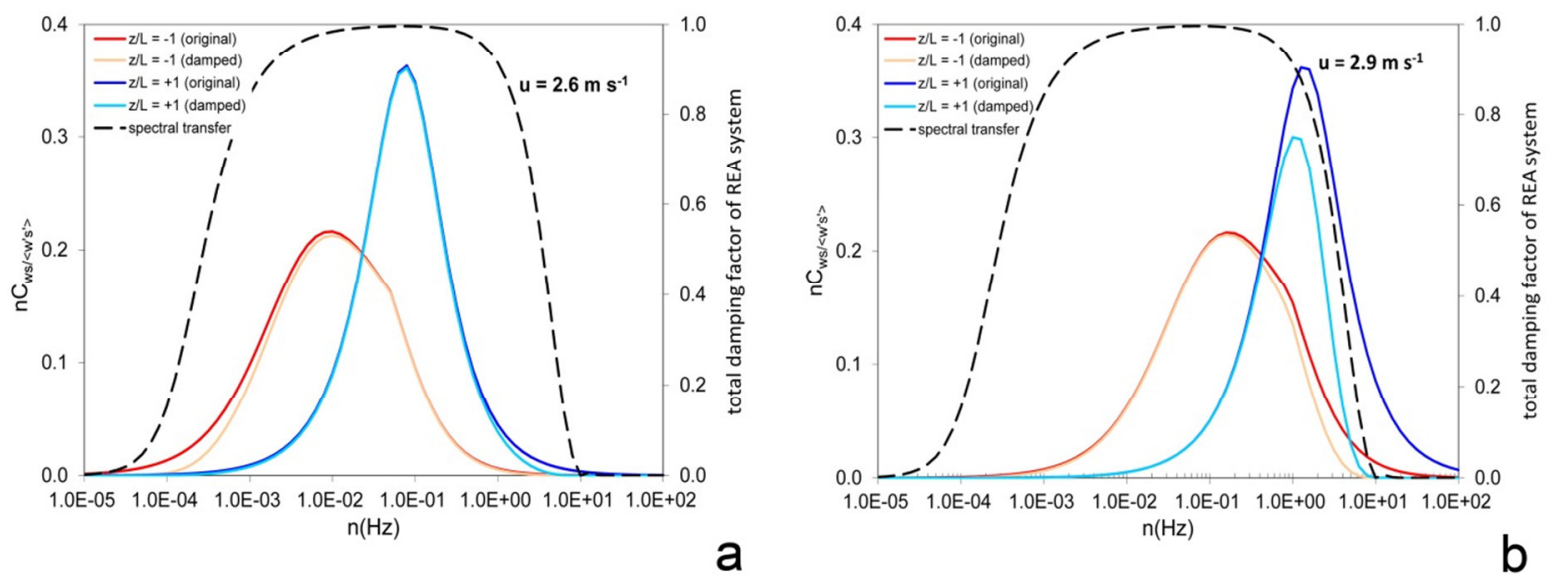

Figure S8. Modeled original and damped cospectral density and total damping factor (secondary y-axis) of REA system for Basel (a) and Degerö (b) dependent on stable $(\mathrm{z} / \mathrm{L}=$ $+1)$ and unstable $(\mathrm{z} / \mathrm{L}=-1)$ conditions and mean horizontal wind speeds for both sites $(\mathrm{u}=2.6$ and $2.9 \mathrm{~m} \mathrm{~s}^{-1}$, respectively). 